\title{
PESQUISA DE FUNGOS DERMATÓFITOS EM AMOSTRAS DE SOLO DE PARQUES RECREACIONAIS DA CIDADE DE ILHÉUS, BAHIA
}

\author{
RESEARCH OF DERMATOPHYTE FUNGUS IN SOIL SAMPLES OF RECREATION \\ PARKS OF THE CITY OF ILHÉUS, BAHIA
}

Maria José Santos de Jesus ${ }^{1}$, Zulane Lima Sousa²

\section{RESUMO}

Fungos dermatófitos são micro-organismos que degradam a queratina presente em substratos humanos e animais e a utilizam como fonte de nutrientes para o seu desenvolvimento, causando infecções denominadas dermatofitoses. Este estudo objetivou pesquisar fungos dermatófitos em amostras de solo de parques recreacionais da cidade de Ilhéus, Bahia. Foram coletadas três amostras de solo de cada um dos oito parques recreacionais localizados em diferentes zonas da cidade. Para o isolamento dos fungos foi utilizada a metodologia de iscas de unhas e cabelos descrita por Vanbreuseghem (1952). As coletas foram realizadas em oito ambientes diferentes utilizados como recurso de lazer para a população. Os critérios de seleção dos ambientes amostrados foram os de intenso fluxo de pessoas, animais e presença de lixo. Das 24 amostras analisadas, apenas 7,14\% dos fungos encontrados estão associados com dermatofitoses. Os outros $92,85 \%$ pertencem à classe dos fungos saprófitas do solo, mas que podem causar dermatomicoses em pessoas com o sistema imunológico comprometido. Os resultados do presente estudo corroboram com outros trabalhos que demonstram a prevalência de fungos saprófitas presente em solos de locais públicos, salientando a necessidade de cuidados especiais com os frequentadores desses locais, sobretudo com as crianças, dado o risco de contrair micoses cutâneas.

${ }^{1}$ Bacharel em Biomedicina, Faculdade Madre Thais (FMT), Ilhéus, Bahia.

E-mail:

maryabiomed@hotmail.com

${ }^{2}$ Bacharel em Biomedicina, Mestre em Biologia e Biotecnologia de Microrganismos e Doutora em Biotecnologia, Docente do curso de Biomedicina da Faculdade Madre Thais (FMT), Ilhéus, Bahia.

E-mail: zulanelima@hotmail.com

Palavras-chave: Dermatófitos. Solo. Micoses cutâneas.

\section{ABSTRACT}

Dermatophyte fungi are microorganisms that degrade keratin present in human and animal substrates and use it as a source of nutrients for its development, causing infections called dermatophytoses. This study aimed to investigate dermatophyte fungi in soil samples from recreational parks in the city of Ilhéus, Bahia. Three soil samples were collected from each of the eight recreational parks located in different areas of the city. For the isolation of the fungi was used the method of nail and hair baits described by Vanbreuseghem (1952). The collections were carried out in eight different environments used as leisure resources for the population. The selection criteria of the sampled environments were those of intense flow of people, animals and presence of garbage. Of the 24 analyzed samples, only $7.14 \%$ of the fungi found are associated with dermatophytoses. The other $92.85 \%$ belong to the class of soil saprophytic fungi, but may cause dermatomycosis in people with compromised immune systems. The results of the present study corroborate other studies demonstrating the prevalence of saprophytic fungi present in soils of public places, stressing the need for special care with the residents of these places, especially with children, given the risk of contracting cutaneous mycoses.

Keywords: Dermatophytes. Ground. Mycoses cutaneous. 


\section{INTRODUÇÃOO}

A natureza é composta de diversos micro-organismos. Dentre eles, os fungos, organismos eucariontes e heterotróficos, que neste ambiente atuam como decompositores de matéria orgânica, onde estão distribuídos em toda sua extensão como, água, ar, solo, além de colonizar a microbiota de animais e humanos. Nos últimos anos, devido às melhorias nos diagnósticos médicos, é possível observar um aumento significativo da incidência de infecções fúngicas, especialmente as micoses superficiais, contraídas por pessoas que frequentam parques de recreações, devido à contaminação do solo. Esse aumento está relacionando com a crescente população de indivíduos imunocomprometidos e outros fatores que causam imunossupressão (SOMENZI; RIBEIRO; MENEZES, 2006).

O solo de áreas recreacionais, quando expostas a fezes e urina de animais e secreções do corpo humano se torna um ambiente propício para a proliferação de microorganismos patogênicos (TORTORA; FUNKE; CASE, 2012). Em determinadas atividades de lazer as pessoas acabam mantendo contato direto com o solo, o que pode configurar uma fonte de contaminação por fungos potencialmente agentes de micoses. O próprio homem e outros animais acabam transmitindo à areia os micro-organismos de que são portadores. Além disso, produzem resíduos que servem de substratos para esses microorganismos potencialmente patogênicos (MAIER et al., 2003).

A queratina é uma proteína sintetizada por muitos animais, responsável por formar diversas estruturas do corpo. Alguns fungos que habitam o solo possuem enzimas capazes de degradar a queratina presente na unha, pele, pelos e cabelos de humanos e animais e a utilizam como fonte de nutrientes, causando lesões no hospedeiro. Dessa forma, esses fungos são chamados de dermatófitos ou queratinofílicos e costumam estar presentes em áreas densamente habitadas como praças, parques escolares e parques públicos (LACAZ et al., 2002).

As dermatofitoses são micoses dos cabelos, pelos, pele e unhas, cujos agentes determinantes são compreendidos no grupo dos dermatófitos, que estão distribuídos entre os gêneros Trichophyton, Epidermophyton e Microsporum. A esse grupo pertencem os fungos filamentosos, septados, hialinos, algumas vezes com artroconídios, queratinofílicos, cuja principal característica é invadir tecidos superficiais queratinizados e causar lesões com quadros clínicos variáveis de infecção cutânea, e eventualmente as lesões subcutâneas (MORAES; LEITE; GOULART, 2008; SIDRIM; ROCHA, 2012). 
Em sua maioria, os dermatófitos produzem dois tipos de estruturas em cultivo: macroconídios e microconídios, que juntamente com as características macroscópicas das colônias, são úteis para identificar as diferentes espécies de dermatófitos (MORAES; PAES; HOLANDA, 2009).

O gênero Trichophyton acomete tanto cabelos e unhas como pele glabra. As colônias de Trichophyton spp variam de uma espécie para outra e geralmente, apresentam colônias veludosas, granulosas, pulverulentas, lisas ou cerosas. A superfície da colônia apresenta cor branca ou amarelada, em alguns casos mais raros, as colônias podem apresentar cor roxa ou cor-de-rosa. Na microscopia, apresentam uma grande quantidade de microconídios piriformes, redondos ou ovalares, ou ainda formando outras estruturas. Quando presentes, os macroconídios possuem aspecto claviforme, alongados e multiseptados com paredes finas e lisas (MORAES, LEITE; GOULART, 2008). As espécies mais isoladas do gênero Trichophynton são T. rubrum, T. mentagrophytes, $T$ violaceum, $T$. tonsurans, T. schoenleinii e T. verrucosum (SANTOS, 2002).

Os dermatófitos do gênero Microsporum atuam como parasitos da pele e raramente das unhas. Em geral, possuem colônias brancas, veludosas ou flocosas com reverso amarelo-ouro. $\mathrm{Na}$ microscopia, apresentam macroconídios grandes, fusiformes e multisseptados de paredes rugosas. As principais espécies isoladas são $M$. nanum, $M$. audouinii, M. canis, M. ferrugineum e M. gypseum. Em patologias humanas, as espécies mais isoladas são o M. canis e o M. gypseum (COSTA et al,. 2002; MORAES, 2009; SIDRIM; ROCHA, 2012).

O gênero Epidermophyton é composto apenas de duas espécies o $E$. stockdalaeae (não dermatófito) e o E. floccosum. Apenas esta última possui importância em patologia humana. É um patógeno exclusivamente de pele glabra, não atinge o cabelo e está presente, sobretudo nas lesões de grandes pregas $e$ interdigitoplantares. Microscopicamente, esse gênero caracteriza-se pela presença de macroconídios claviformes, agrupados em um único ponto na extremidade distal da hifa, conferindo um aspecto de "penca de bananas", sem presença de microconídios. Possui um crescimento rápido, podendo observar colônias maduras num período de 7-10 dias. Macroscopicamente, observa-se colônias com textura algodonosa baixa, umbilicada, evoluindo para pulverulenta na porção intermediária. As bordas do revesso da colônia possuem coloração amarelo-esverdeada ou, ainda, rubra (SIDRIM; ROCHA, 2012). 
Estes micro-organismos podem ainda ser divididos em grupos, tendo em consideração o seu habitat e afinidade com o substrato, podendo ser classificados em antropofílicos, zoofílicos e geofílicos. As espécies antropofílicas podem sofrer influência de fatores sociológicos, ambientais, étnicos e antropogênicos (hábitos de higiene), compatibilidade com diversos tipos de queratina e são adaptadas aos seres humanos, não excluindo os animais; os zoofílicos possuem reservatório em animais, principalmente cães e gatos, e podem ser transmitidos para seres humanos; os geofílicos não causam infecções em humanos ou em outros animais (SIDRIM; ROCHA, 2012; COSTA et al., 2002).

As dermatofitoses estão classificadas de acordo com as localizações anatômicas acometidas pelos fungos e estão relacionadas com todas as infecções de tínea, que também está associada à outra palavra, que ressalta o sítio anatômico da lesão. As lesões de tínea são denominadas de tínea capitis (couro cabeludo), tínea pedis (pés), tínea corporis (corpo), tínea cruris (grandes pregas), tínea unguium (unhas) e tínea barbae (barba). Todavia, em determinadas situações, os dermatófitos podem invadir o extrato córneo e colonizar as camadas mais profundas e provocar três quadros clínicos. São eles granuloma tricofítico, micetoma dermatofítico e doença dermatofítica. Tais situações vão depender da espécie do dermatófito e estado imunológico do hospedeiro (SIDRIM \& ROCHA, 2012). O quadro clínico vai depender do local da lesão e tipo de fungo causador da micose. Geralmente se caracteriza por lesões superficiais, com bordas descamativas, circulares, pruriginosas e eritematosas (SOMENZI; RIBEIRO; MENEZES, 2006).

A tínea do corpo (tínea corporis) é caracterizada por lesões com bordas bem definidas, descamativas, eritematosas e pruriginosas. A tínea do pé (tínea pedis) é bastante comum em pessoas que fazem o uso de sapatos fechados. As lesões agudas ocorrem entre os dedos, com mau odor, maceração e prurido. Na forma crônica, ocorre descamação seca dos pés. No couro cabeludo (tínea capitis), as lesões são descamativas com placas de alopécia (sem cabelos), e normalmente apresenta queda de cabelos. Nas unhas (tínea unguium), há deslocamento de parte da unha, com aspecto amarelado ou esbranquiçado, poroso e grosso (RODRIGUES et al., 2010).

As dermatofitoses afetam cerca de $25 \%$ da população mundial, estando entre as doenças mais prevalentes do mundo. As condições de temperaturas, aspecto sócioeconômico, imunidade do hospedeiro e idade constituem fatores importantes para a sua disseminação, sendo mais prevalentes em países tropicais, contistuindo um grave problema de saúde pública (BRILHANTE et al., 2000). Já de acordo com a faixa etária, há 
preferência por crianças, por ser o grupo mais exposto aos fatores de risco, tais como: hábitos higiênicos precários, contato direto com animais domésticos, contato com areia e aglomerações em creches e escolas (PROENÇA; ASSUMPÇÃO, 1991).

Dados epidemiológicos apontam que as dermatofitoses estão entre as doenças dermatológicas mais predominantes no Brasil, mas pelo fato de não ser doenças de notificação compulsória, há uma escassez de dados nacionais de prevalência das mesmas. O que existe apenas são dados isolados de publicações nos serviços de dermatologia existentes nas capitais. A maioria das dermatomicoses são autotratadas, e grande parte nem chega ao conhecimento dos especialistas, e as que são atendidas, não são tratadas com os cuidados que a situação merece (BRASIL, 2006).

$\mathrm{Na}$ cidade de llhéus - Ba não há publicações sobre a epidemiologia das dermatofitoses, sendo este o primeiro estudo a tratar tais aspectos. Desse modo, torna-se evidente a importância da investigação, com o propósito de estudar a frequência de agentes etiológicos de dermatofitoses em parques recreacionais, considerando que esses locais são utilizados como recurso de lazer por algumas pessoas, no qual as mesmas mantêm um contato direto com o solo, facilitando a contaminação por agentes causadores de micoses.

Diante do exposto, considerando o uso de parques recreacionais como recurso de lazer por adultos e crianças, o objetivo do presente estudo foi verificar a presença de fungos dermatófitos em amostras de solo de parques de recreações no município de llhéus, Bahia.

\section{MATERIAIS E METODOS}

Os oito parques de recreações incluídos neste estudo são revestidos de terra e areia localizados em bairros da zona norte, zona sul, zona oeste e centro do município de Ilhéus, Ba (figura 1 a 4).

A coleta foi realizada em três pontos diferentes de cada parque, sempre coletando de locais onde o trânsito de pessoas e de animais era mais intenso ou que houvesse a presença de lixo no local.

As amostras de solo foram coletadas em março de 2018 de cada parque com o auxílio de uma espátula estéril. O material foi acondicionado em frascos coletor universal estéril, devidamente identificados, transportados e armazenados a temperatura ambiente no laboratório de Microbiologia - FMT. 
DOI: 10.18605/2175-7275/cereus.v12n1p77-90 Revista Cereus
JESUS, MJS. SOUSA, ZL

Pesquisa de fungos dermatófitos em amostras de solo de parques recreacionais da cidade de llhéus, Bahia

A identificação das amostras foi realizada de acordo com a sequência numérica dos bairros, seguida das letras A, B e C, correspondente a cada triplicata (Tabela 01).

Tabela 1 - Localização e número das amostras coletada em parques recreacionais de Ilhéus, Bahia.

\begin{tabular}{cc}
\hline Amostra & Bairro \\
\hline 01 & Sapetinga \\
02 & Pontal \\
03 & Hernani Sá \\
04 & Cidade Nova \\
05 & Iguape \\
06 & Morada do Bosque \\
07 & Morada do Porto \\
08 & Couto \\
\hline
\end{tabular}

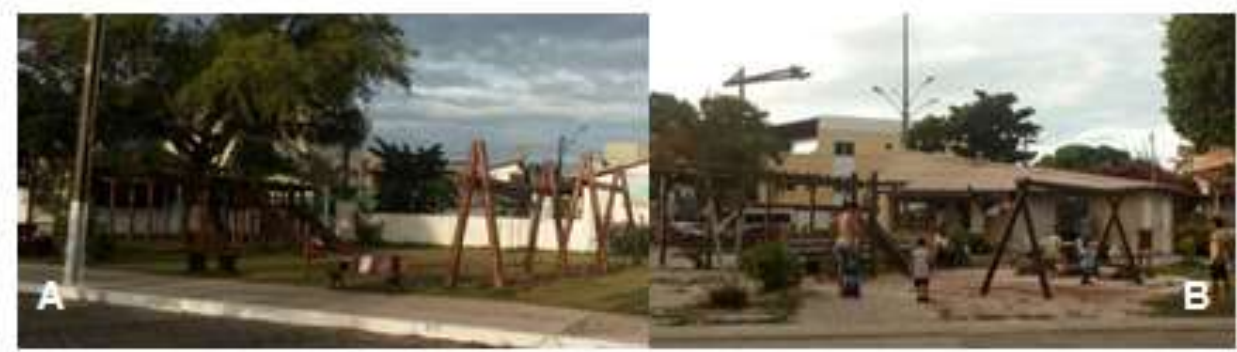

Figura 1: Vista dos parques localizados nos bairros Sapetinga (A) e Pontal (B), onde foram obtidas as amostras 01 e 02 , respectivamente.

Fonte: próprio autor

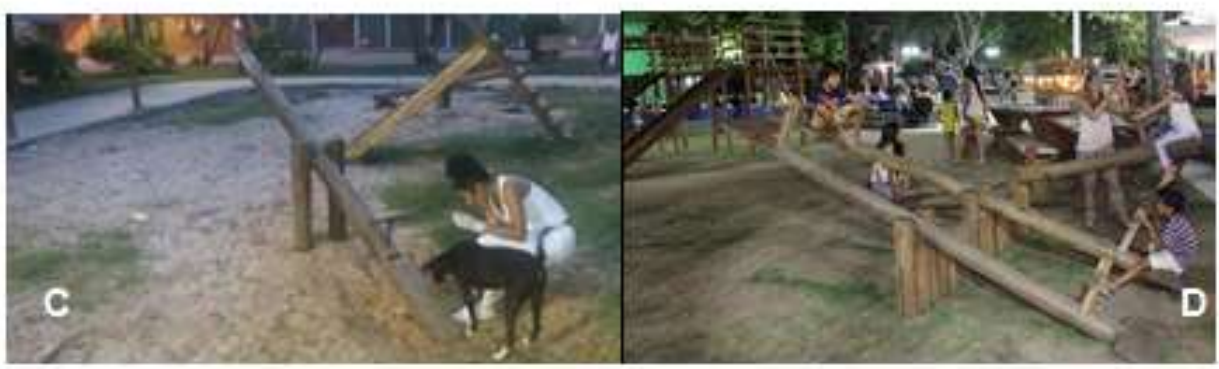

Figura 2: Vista dos parques localizados nos bairros Hernani Sá (C) e Cidade Nova (D), onde foram obtidas as amostras 03 e 04 , respectivamente.

Fonte: próprio autor

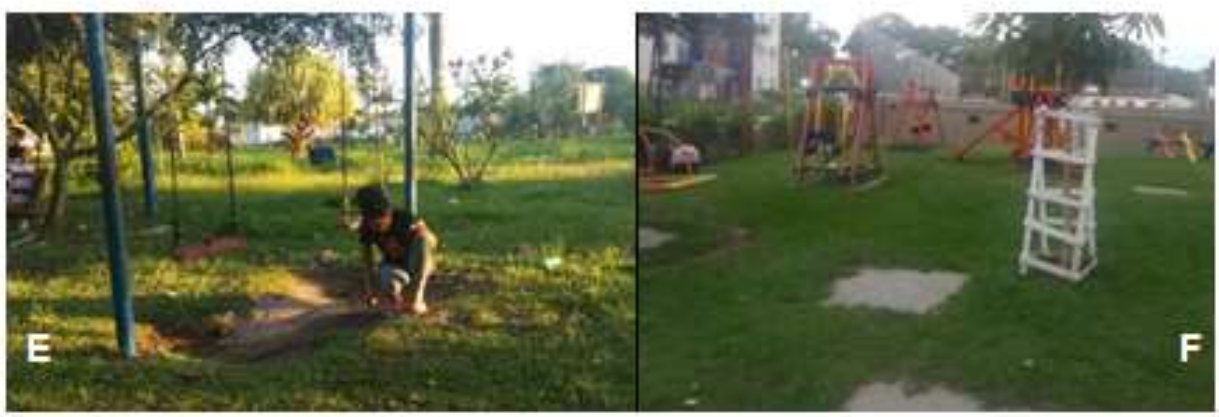

Figura 3: Vista dos parques localizados nos bairros Iguape (E) e Morada do Bosque (F), onde foram obtidas as amostras 05 e 06 , respectivamente.

Fonte: próprio autor 


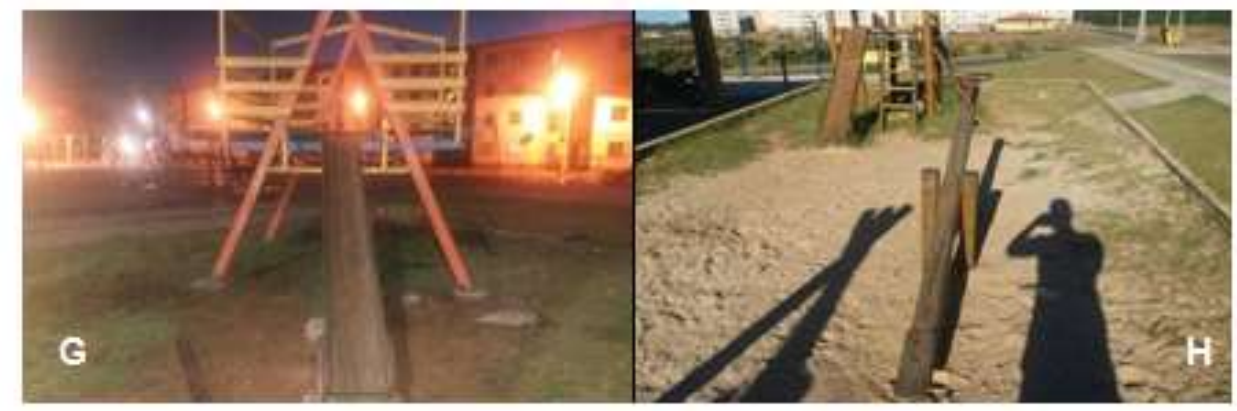

Figura 4: Vista dos parques localizados nos bairros Morada do Porto $(G)$ e Couto $(H)$, onde foram obtidas as amostras 07 e 08 , respectivamente.

Fonte: próprio autor

O isolamento dos fungos queratinofílicos foi realizado de acordo com a metodologia descria por Vambreuseghem (1952), com algumas modificações, como segue: Aproximadamente 15 gramas da amostra de cada local de coleta foram distribuídas em placas de Petri contendo meio de cultura Ágar Saboraud Dextrose previamente esterilizados, às quais foram adicionadas $3 \mathrm{ml}$ de água destilada estéril. Pequenos fragmentos de unhas e tufos de cabelos previamente esterilizados foram distribuídos em quatro pontos da placa, sendo dois tufos de cabelos e dois fragmentos de unhas, com três repetições por amostra, totalizando 24 placas. As placas foram mantidas a $25^{\circ} \mathrm{C}+/-2^{\circ} \mathrm{C}$ por 15 dias e observadas diariamente para monitorar a presença de colonização fúngica.

Fragmentos de unha e cabelo que apresentavam crescimento fúngico foram transferidos para tubos de ensaio contendo Ágar Sabouraud acrescido de Cloranfenicol e mantidos a $25^{\circ} \mathrm{C}+/-2^{\circ} \mathrm{C}$ por um período de 5 a 10 dias. Após esse período foi realizada a descrição macromorfológica dos fungos e, em seguida, foi realizado o microcultivo dos fungos isolados.

A identificação taxonômica dos fungos foi baseada no ensaio de microcultivo em lâmina. Este método de Riddall (LACAZ et al., 2002) proporciona a preservação da integridade das estruturas fúngicas e o estudo detalhado da disposição das diferentes estruturas ao longo das hifas.

A cultura foi montada por meio de um corte, com bisturi, de quadrados de Ágar Batata e colocados sobre uma lâmina de microscopia estéril. Pequenos fragmentos do fungo a ser estudado e identificado foram depositados em cada lateral do quadrado, fazendo perfurações com uma alça de inoculação. Os quadrados foram cobertos com uma lamínula e o conjunto foi incubado dentro de uma placa de Petri estéril, em câmera úmida, e mantido a $25^{\circ} \mathrm{C}+/-2^{\circ} \mathrm{C}$ por um período de tempo que variou de 3 a 5 dias. Após esse período, a lamínula com o micélio aderido foi removida do quadrado de ágar e montada 
sobre uma lâmina contendo o corante Lactofenol Azul de Algodão. A lâmina foi levada ao microscópio para pesquisa das estruturas e órgão de reprodução a fim de identificar o gênero de fungo encontrado, na objetiva de 40X, onde foi realizado o registro fotográfico.

\section{RESULTADOS E DISCUSSÄO}

Foram analisadas um total de 24 amostras de solo de 8 parques recreacionais, das quais todas foram positivas para a presença de fungos filamentosos.

Das 24 amostras positivas, foram identificados 9 gêneros de fungos filamentosos nas diferentes amostras, foram estes: Aspergillus sp. Acremonium sp., Fusarium sp., Rhizopus sp., Mucor sp., Epidermophyton floccosum, Gliocladium sp., Cunninghamella sp. e Trichoderma sp. (Figura 5).

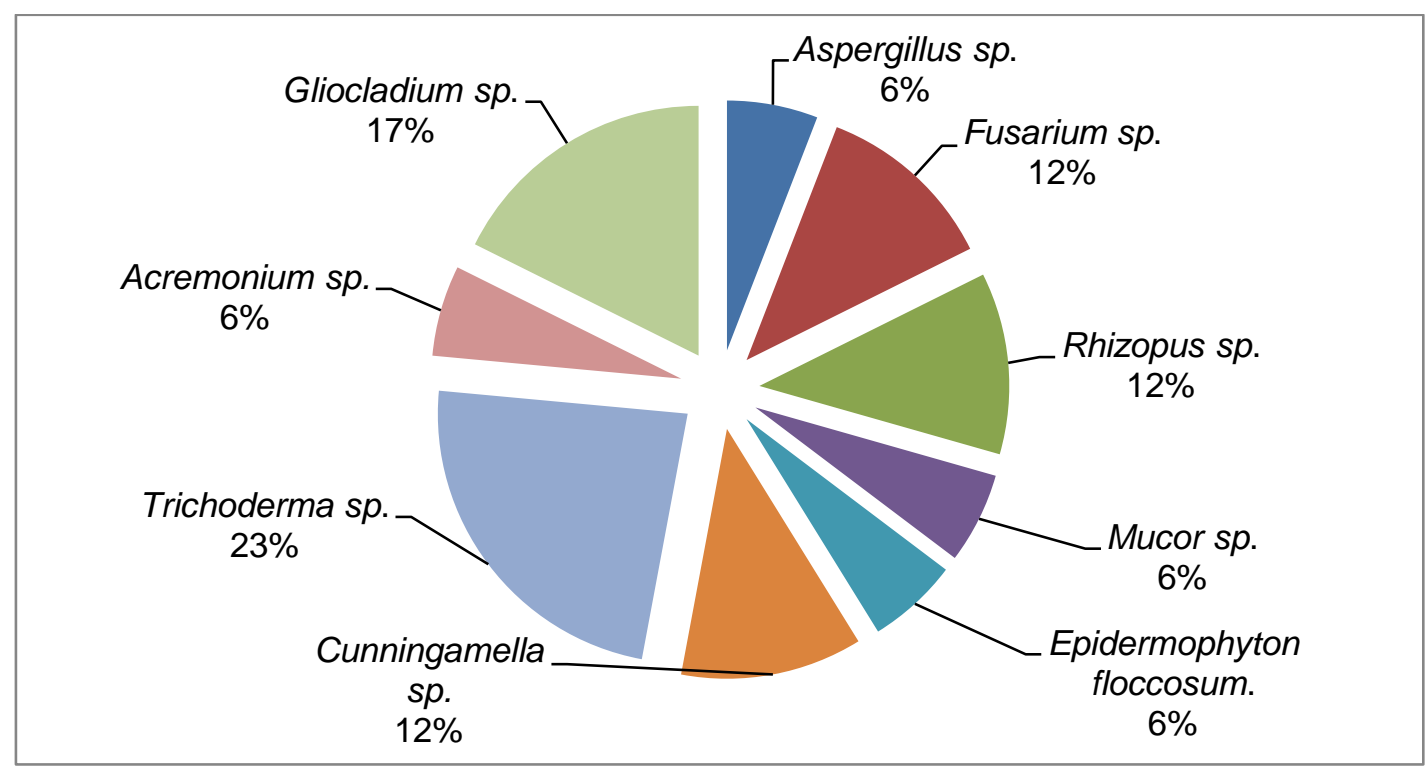

Figura 5. Distribuição de gêneros de fungos identificados em 24 amostras de solo de solo de parques recreacionais em llhéus, Bahia

Fonte: próprio autor

Os resultados exibidos na figura 5 demonstram que o gênero Trichoderma foi o mais frequentemente isolado, representando uma frequência relativa de $23,00 \%$, seguido dos gêneros Gliocladium com 17,00\% e Fusarium, Rhizopus e Cunninghamella, ambos com $12,00 \%$. Os demais gêneros em conjunto, representaram 24\% da frequência relativa. Estes resultados podem ser justificados pelo fato dos gêneros Gliocladium, Fusarium, Rhizopus e Cunninghamella serem fungos encontrados em diferentes substratos, atuando como sapróbios do solo (OLIVEIRA, 2013). 
Entre os fungos detectados, foi verificado que um deles pertence ao grupo dos fungos dermatófitos, enquanto que os demais abrangem os fungos não dermatófitos (Tabela 2). O gênero caracterizado como dermatófito foi Epidermophyton floccosum. (agente etiológico de dermatofitoses), isolado através da amostra de solo do parque Morada do Bosque (amostra seis) totalizando $6,0 \%$.

Tabela 2. Número de fungos filamentosos dermatófitos e não dermatófitos isolados de amostras de solo de parques recreacionais no município de llhéus, Ba

\begin{tabular}{ccc}
\hline IDENTIFICAÇÃO & NÚMERO DE COLÔNIAS & PORCENTAGEM (\%) \\
\hline Dermatófitos & 02 & 7,14 \\
Não dermatófitos & 26 & 92,85 \\
TOTAL & 28 & 100 \\
\hline
\end{tabular}

A figura 6 representa a microscopia dos nove gêneros isolados de amostras de solo de parques recreacionais no município de Ilhéus, Bahia.
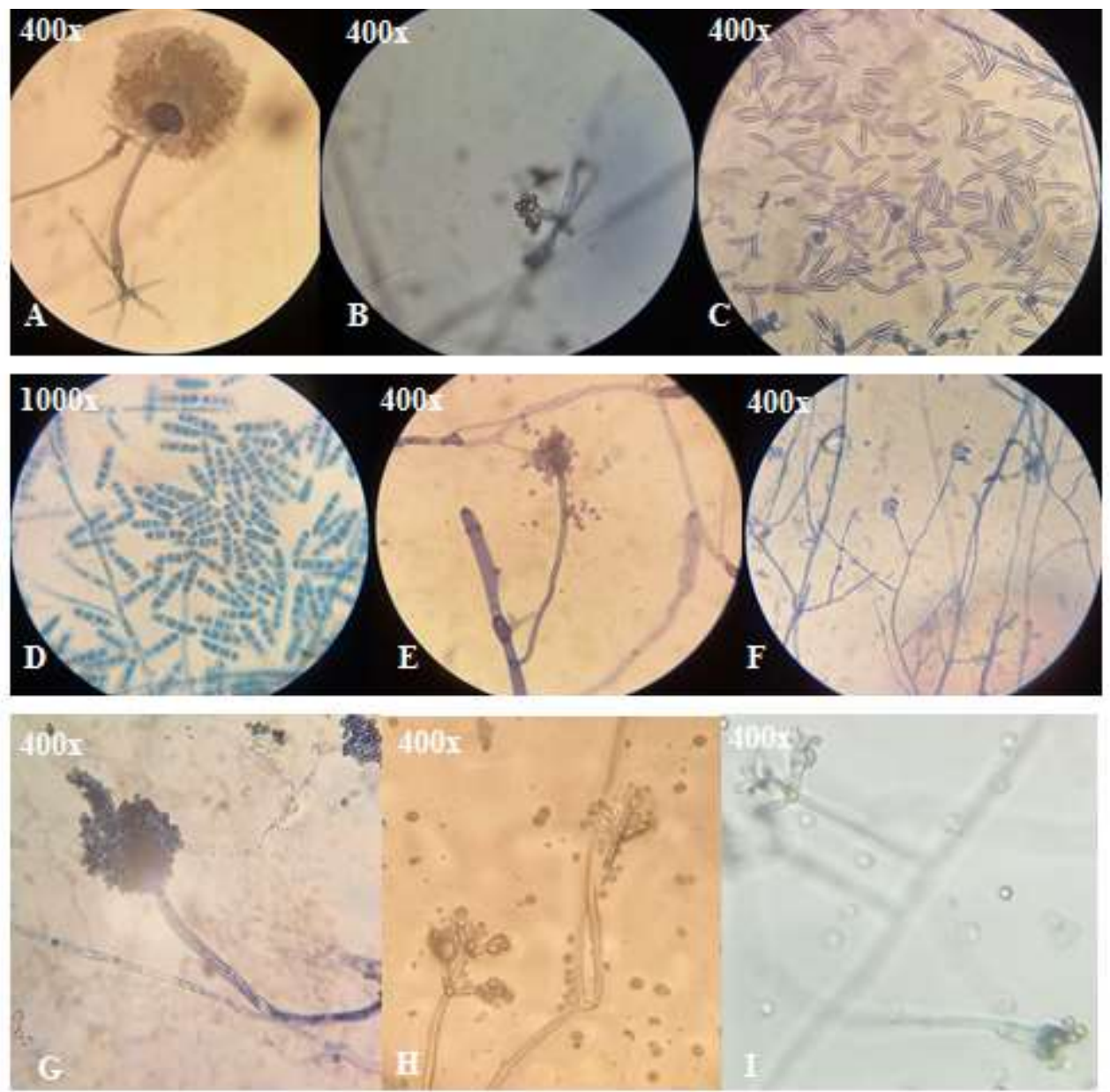

Figura 6. Microscopia dos fungos identificados: A) Rhizopus sp.; B) Cunninghamella $s p$;; C) Fusarium sp.; D) Epidermophyton floccosum; E) Mucor sp.; F) Acremonium sp.; G) Aspergillus sp.; H) Gliocladium sp.; I) Trichoderma sp. 
Fonte: próprio autor

A qualidade ambiental de parques de recreação possui grande relevância para a saúde pública, visto que, o solo possivelmente contaminado pode disseminar inúmeras doenças causadas por parasitas, tais como, os fungos (BERNARDI et al., 2015).

Neste trabalho, com o objetivo de pesquisar a presença de fungos dermatófitos em parques recreacionais de Ilhéus-Ba, foi observado que, das 24 amostras analisadas, somente $7 \%$ correspondem a gêneros relacionados à dermatofitoses em humanos e animais. Os outros $93 \%$ dos fungos isolados são originados do solo, ou seja, são espécies saprófitas que habitam o solo normalmente, mas que podem estar relacionadas com dermatomicoses - micoses causadas por fungos que atingem a pele, porém, não causam a degradação da queratina, especialmente as oportunistas que provocam lesões na pele, pelos e unhas, sobretudo em pacientes imunocomprometidos, e processos alérgicos relacionados à micotoxinas produzidas por fungos do gênero Aspergillus e Trichoderma, por exemplo.

Mello, Ribeiro e Fortes (2007) e Souza e Araújo (2007), em sua pesquisa utilizando a técnica de iscas, identificaram a presença de fungos como Penicillium sp., Aspergillus sp., Fusarium sp., Chrysosporium sp., Verticillium sp., Acremonium sp., Sincephalastrum sp. Neste trabalho foi identificado a presença de Aspergillus sp. (Agente etiológico da Aspergilose), Acremonium sp. (Agente causador de infecções oportunistas) e Fusarium sp. (Agente etiológico de onicomicoses e oftalmomicoses).

De acordo com Ninet et al., (2004) em sua pesquisa utilizando técnicas moleculares para identificar espécies de Fusarium obtidas através de amostras de casos de onicomicoses, relataram que $F$. oxysporum, $F$. solani, $F$ proliferatum e $F$. dimerum foram as espécies mais encontradas, correspondendo a 54,0\%, 33,0\%, 9,9\% e 1,4\%, respectivamente. Os autores ainda complementam que em pacientes imunocomprometidos, as espécies estudadas podem causar fusariose disseminada. Em casos de onicomicoses, a presença dessas espécies requer atenção nos casos de pacientes em tratamento de imunossupressão.

Segundo Maier (2003) e Lacaz et al (2002), o gênero Aspergillus é um fungo filamentoso encontrado no ambiente que pode causar diversas complicações em indivíduos imunodeprimidos. As principais complicações são: Apergilose invasiva que pode ser encontrada em localizações variadas como as unhas após sofrer traumatismo ou cavidade pulmonar, leões isquêmicas, em indivíduos com psoríase e eczemas crônicos. 
Outros gêneros foram identificados no presente trabalho, como: Rhizopus sp. (agente etiológico da mucormicose), Trichoderma sp. (produtor de micotoxinas), Mucor sp. (agente de micoses cutâneas) e Gliocladium sp. (agente de infecção oportunista).

Segundo Moreira e Siqueira (2002), os gêneros Penicillium sp., Aspergillus sp., Trichoderma sp., Mucor sp., Rhizopus sp., Alternaria sp., Fusarium sp., Pythium sp. e Lecancillium sp., são fungos que possuem seu habitat no solo, de onde são frequentemente isolados. Em partes, o presente estudo corrobora com esses dados, uma vez que, Fusarium sp., Aspergillus sp., Trichoderma sp., Rhizopus sp. e Mucor sp. foram gêneros isolados e corresponderam a $59 \%$ do total.

Apesar dos resultados do presente estudo não terem refletido um elevado percentual de agentes de dematofitoses presentes no solo, especialmente em áreas frequentadas por humanos e animais, parques de recreações possuem uma grande variedade de fungos saprofíticos, desempenhando a sua função de decompositores de matéria orgânica presente no solo, que eventualmente podem provocar micoses oportunistas em pessoas que frequentam esses parques, sobretudo em indivíduos com o sistema imunológico fragilizado (TAKAHASHI et al., 2011).

O sistema imunológico da criança ainda não está totalmente formado na infância. Nessa fase, a proteção contra doenças infecciosas se dá através das imuniglobulinas lgG passivamente adquiridos transplacentariamente e por meio do leite materno. Quando essa imunidade falha, a criança pode estar susceptível a inúmeras doenças contagiosas causadas por vírus, bactérias, parasitas e fungos, embora essa imunidade seja reforçada mais tarde com o amadurecimento da imunidade inata e adquirida (SIMON; HOLLANDER, McMICHAEL, 2015). A presença de fungos dos gêneros não dermatófitos representa o potencial risco de contaminação nos ambientes estudados, pois, é sabido que tanto os fungos dermatófitos quanto os não dermatófitos podem ser potencialmente capazes de causar lesões cutâneas em humanos e animais, principalmente em crianças, devido ao contato direto com o solo e animais domésticos (GUGNANI, 2003).

Dessa forma, é importante ressaltar que quando se deseja assegurar e aprimorar a saúde pública, a qualidade ambiental do solo utilizado em parques recreacionais deve ser um fator importante a ser considerado, pois, o mesmo pode ser um veículo de transmissão de patógenos, incluindo os fungos (BERNARDI et al., 2015). 


\section{CONCLUSÖES}

Os resultados desta pesquisa demonstraram que no solo de parques recreacionais analisados no município de Ilhéus - Ba há a presença de fungos filamentosos dermatófitos, bem como a presença significativa de fungos do gênero não dermatófitos, que também participam do processo de degradação de matéria orgânica do solo, e que em condições de imunossupressão podem causar infecções oportunistas em humanos, ambos os gêneros sendo importantes para a saúde pública.

Embora o presente estudo tenha mostrado um percentual pequeno de gêneros relacionados à dermatofitoses, outros estudos devem ser realizados com a finalidade de avaliar o potencial patogênico dos gêneros não dermatófitos isolados nesse estudo.

Vale salientar a importância de levar essas informações até as autoridades governantes e para a população em geral, para que medidas de prevenção e controle higiênico-sanitário como, calçamento dos parques de recreações e limpeza diária para evitar acúmulo de lixo, sejam tomadas por esses indivíduos.

\section{REFERENCIAS}

BERNARDI, A. C. A.; SILVA, J. L. M.; SOUTO, A. P. G.; ALMEIDA, C. C. Estudo de Fungos Queratinofílicos Geofílicos em Praças Públicas de Jaboticabal-SP. Revista Brasileira Multidisciplinar, (Unirana). v. 12, n. 2, p. 79-88, 2015.

BRASIL. Ministério da Saúde. Secretaria de Atenção à Saúde. Dept ${ }^{\circ}$ de Ações Programáticas Estratégicas. Dermatoses Ocupacionais. Saúdde do Trabalhador. Protocolos de Complexidade Diferenciada n.ํํㅇ. Série A. Normas e Manuais Técnicos. Brasília. DF. 2006.

BRILHANTE, R. S. N.; PAIXÃO, G. C.; DIÓGENES, M. J. N.; BANDEIRA, S. P.; ROCHA, M. F. G.; SIDRIM, J. J. C. Epidemiologia e ecologia das dermatofitoses na cidade de Fortaleza: O Trichophyton tonsurans como importante patogeno emergente da Tinea capitis. Revista da Sociedade Brasileira de Medicina Tropical, v. 33, p. 417-425, 2000.

COSTA, E. C.; SOUZA, C. M.; CAVALCANTE, M. A. Q.; FERNANDES, M. J; LIMA, D. M. $M$. Fungos queratinofilicos isolados de um parque escolar do Recife-PE. Anais do 53ํㅡㄹ Congresso Nacional de Botânica, v.52, n.3,p. 259-260, 2002.

GUGNANI, H. C. Nodermatophytic filamentous keratinophilic fungi and their role in human infection. Polish journal of Environmental Studies, v. 12, p. 461-466, 2003.

LACAZ, C. S.; PORTO, E.; MARTINS, J. E. C..; VACCARI, E. V.; MELO, N. T.

Tratado de micologia médica Lacaz. 9 ed. São Paulo: Sarvier; 2002. 
MAIER, L. M.; OLIVEIRA, V. R.; REZENDE, K. C. R.; VIERIRA, V. D. R.; CARVALHO, C. R. Avaliação da presença de fungos e bactérias patogênicas nas areias de duas praias de baixo hidrodinamismo e alta ocupação humana no litoral do município do Rio de Janeiro, Rio de Janeiro. Coleção estudos da cidade. 2 ed.jun/ jul. 2003. 43p.

MELLO, M. P. M. ; RIBEIRO, T. P. S. ; FORTES, S. T. Fungos Queratinofílicos isolados de areia de parques escolares em Boas Vista-RR. In: Encontro de Pesquisa e Iniciação Ciêntifica da UFRR, 2007. Boa Vista - RR. CD do encontro. 2007.

MORAES A. M. L.; PAES, R. A.; HOLANDA, V. L. Micologia. Rio de Janeiro: EPSJV. Cap. 4, p. 399-496, 2009.

MORAES, R. G.; LEITE, I. C.; GOULART, E. Parasitologia \& Micologia Humana. 5ํㅡ. Rio de Janeiro: Guanabara Koogan, 2008.

MOREIRA, F. M. S.; SIQUIERA, J. O. Microbiologia e Bioquímica do Solo. Lavras: Editora UFLA, p. 243-284, 2002.

NINET, B.; JAN, I.; BONTEMS, O.; LÉCHENNE, B.; JOUSSON, O.; LEW, D.; SCHRENZEL, J.; PANIZZON, R.G. \& MONOD, M. 2004. Molecular identification of Fusarium Species in onychomycoses. Dermatology, v. 210, p. 21-25, 2004.

OLIVEIRA, L. G. Dversidade e potencial enzimático de fungos filamentosos isolados do solo, Semi-Árido, Pernambuco, Brasil. Tese (doutorado) - Universidade Federal de Pernambuco, Centro de Ciências Biológicas, Pós-graduação em Biologia de Fungos, 2013.

PROENÇA, N. G.; ASSUMPÇÃO, S. B. P. Dermatofitoses observadas em crianças com 0-12 anos de idade em São Paulo. Rev. Inst Méd Trop... v.21, n..3, p.146-8,1991.

RODRIGUES, D. A.; TOMIMORI, J.; FLORIANO, M. C.; MENDONÇA, S. Atlas de dermatologia em povos indígenas [online]. São Paulo: Editora Unnifesp, 2010. Doenças causadas por fungos, p. 59-80.

SANTOS, J. L.; COELHO, M. P. P.; NAPPI, B. P. Diagnóstico Laboratorial das Dermatofitoses. RBAC. 34(1):3-6, 2002.

SIDRIM, J. J.; ROCHA, M. F. G.; Micologia à Luz dos Autores Contemporâneos. Ed. Guanabara Koogan, 1ํ Edição, 2012.

SIMON, A. K.; HOLLANDER, G. A. McMICHAEL, A. Evolution of the immune system in humans from infancy to old age. Proc. R. Soc. B 282: 20143085.

http://dx.doi.org/10.1098/rspb.2014.3085

SOMENZI, C. C.; RIBEIRO, T. S.; MENEZES, A. Características particulares da micologia clínica e o diagnóstico laboratorial de micoses superficiais. Newslab. 2006; 77:106-18.

SOUZA, A. K. P.; ARAUJO, M. A. S. Isolamento de fungos queratinofílicos do solo de praças e areia de praia do município de Maceió, Alagoas. In: Congresso Brasileiro de 
Micologia, 2007, Recife. Micologia Avanços no Conhecimento. Recife-PE: Universitária da UFPE, 2007. v. 5. p. 5-376. 2007.

TAKAHASHI, J. P.; PELEGRINI, A.; PEREIRA, C. Q. M.; SOUZA, M. C. Levantamento de Fungos Queratinofílicos em Solo de Parques e Praças Públicas no Município de São Bernardo do Campo. Revista de Biologia e Ciências da Terra, v. 11, n. 1, p. 47-53, 2011.

TORTORA, G. J.; FUNKE, B. R.; CASE, C. L. 2012. Microbiologia. 10. Ed. Porto Alegre, Arrmed.

VANBREUSEGHEM R. Keratin digestion by dermatophytes: a specific diagnostic method. Mycologia, Lancaster, v. 44, p. 176-182, 1952. 